\title{
Onset separation aerodynamics of Crew Module from Crew Escape System
}

\author{
R. Saravanan ${ }^{1}$, J. A. Tennyson ${ }^{1}$, S. L. N. Desikan ${ }^{1, *}$, M. M. Patil ${ }^{2}$, \\ R. Kalimuthu ${ }^{3}$ and Surendranath ${ }^{4}$ \\ ${ }^{1}$ Wind Tunnel Data Division, and \\ ${ }^{2}$ Aerodynamic Design and Synthesis Group, Vikram Sarabhai Space Centre, Thiruvananthapuram 695022 , India \\ ${ }^{3}$ Cryo and Semicryo Subsystem Test Facilities, ISRO Propulsion Research Complex, Mahendragiri 627 133, India \\ ${ }^{4}$ Department of Aerospace Engineering, Indian Institute of Science, Bengaluru 560012 , India
}

Aerodynamic characteristics of Crew Module (CM) during its separation from the Crew Escape System (CES) are essential to carry out separation dynamics analysis for confirming collision-free separation. As $C M$ is at the base of CES, it has to clear the complex wake flow that prevails in the aft region. A $1: 10$-scale wind tunnel model is tested at $45 \mathrm{~m} / \mathrm{s}$ freestream velocity in Indian Institute of Science, Bengaluru lowspeed tunnel. The interaction of $C M$ with the base flows is studied for different attitude conditions in terms angle of attack, longitudinal and lateral movements. Results indicate that $\mathrm{CM}$ is recovered from forebody influence beyond $X / D=2$, and it experiences reverse flow till it moves to $X / D=1.4 D$. Stability characteristics of $C M$ are also analysed.

Keywords: Aerodynamics, Crew Models, Crew Escape System, stability characteristics, wind tunnel.

\section{Introduction}

THE first pad abort mission of Indian Space Research Organisation's (ISRO) Crew Escape System (CES) was successfully test fired on 5 July 2018 (Figure 1). The CES-Pad abort configuration has a combination of spherical cone, cylinder, flare and shroud geometry. Vehicle forward structure has a length of $8 \mathrm{~m}$, which houses the CES Jettison Motor (CJM), Pitch Motor (PM) and Lowaltitude Escape Motor (LEM). The four reverse-flow nozzles of LEM are located in the middle of the forward structure. Vehicle forward structure is followed by conical shroud and cylinder, CM Fairing (CMF). The overall height, diameter and half cone angle of CMF are $5.4 \mathrm{~m}$, $3.7 \mathrm{~m}$ and $30^{\circ}$ respectively, that houses the Crew Module (CM) and High altitude Escape Motor (HEM) with scarf nozzle flushed with external surface. The aft portion of CES is attached with cruciform grid fins to ensure sufficient static stability under jet-on and jet-off phases. The vehicle lift-off mass is 13 tonnes and total length is $14 \mathrm{~m}$. LEM and HEM provide sufficient acceleration levels to

*For correspondence. (e-mail: sln_desikan@vssc.gov.in) move out of the launch pad and PM provides lateral range with pitch manoeuvre.

This abort mission is strategically important due to the fact that the future flight is a human-rated vehicle in which various abort sequences need to be qualified for the safety of astronauts from launch pad onwards. In the case of any adverse eventuality at the launch pad, the CES will be taken from the launch vehicle. The purpose of CES is to save the crew in case of abort during the first stage of the ascent flight. During the first stage,

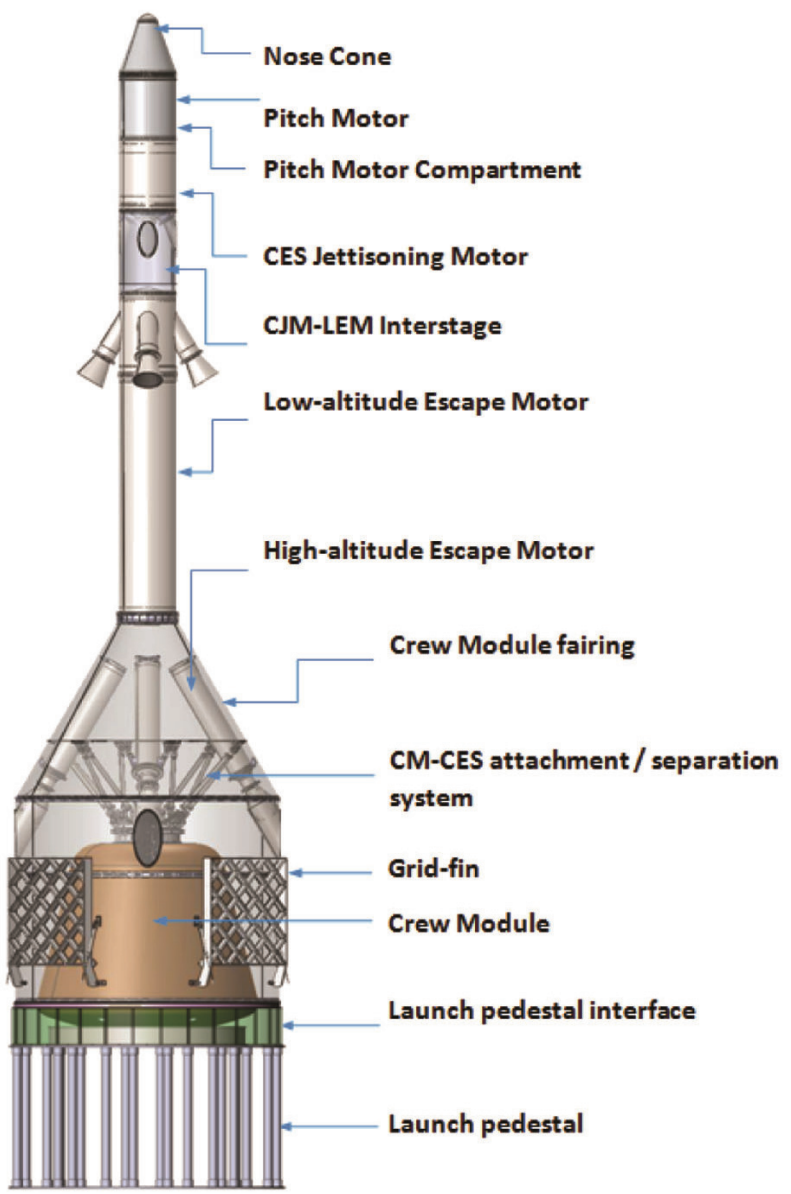

Figure 1. Crew Escape System Pad Abort Configuration. 


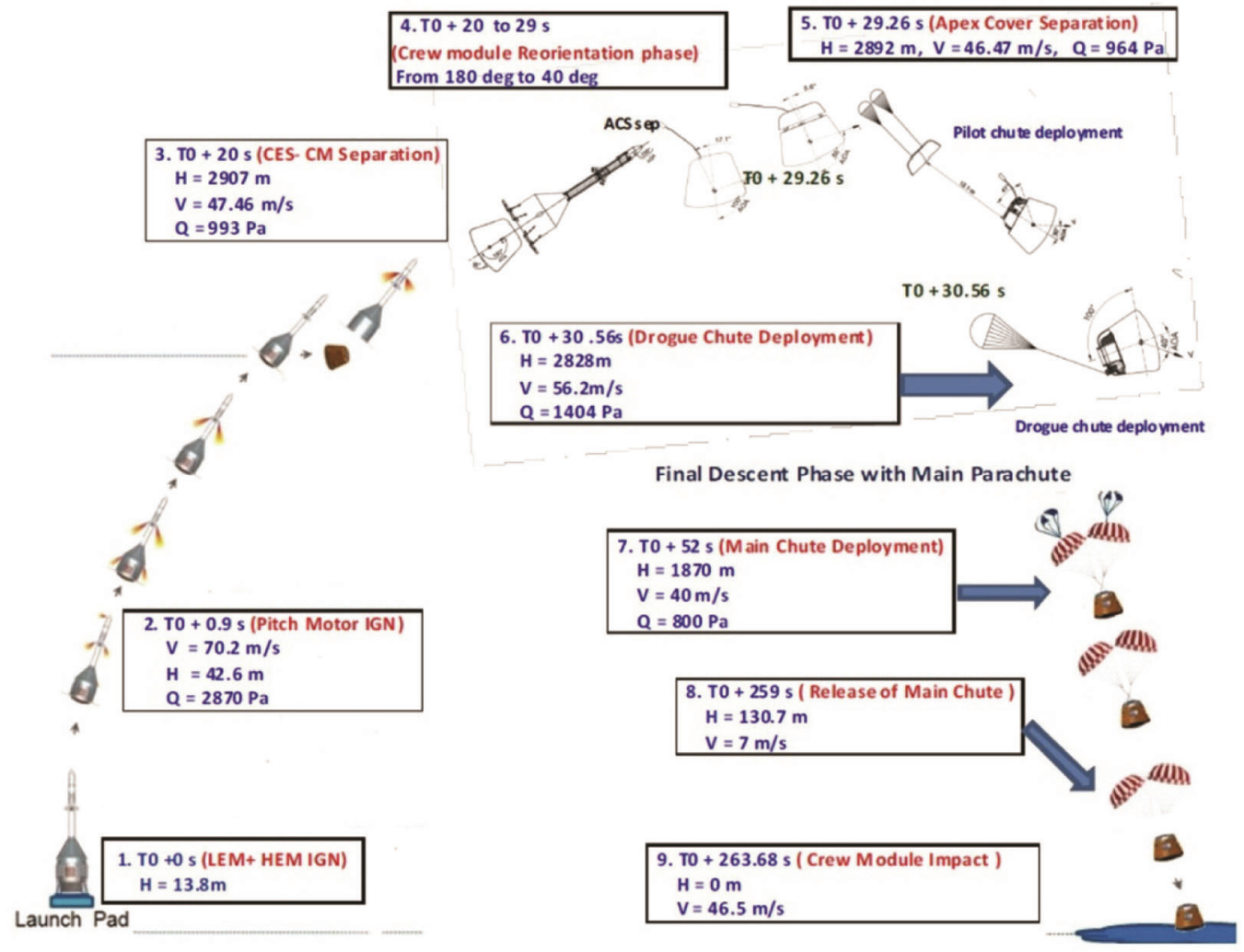

Figure 2. Pad abort mission profile.
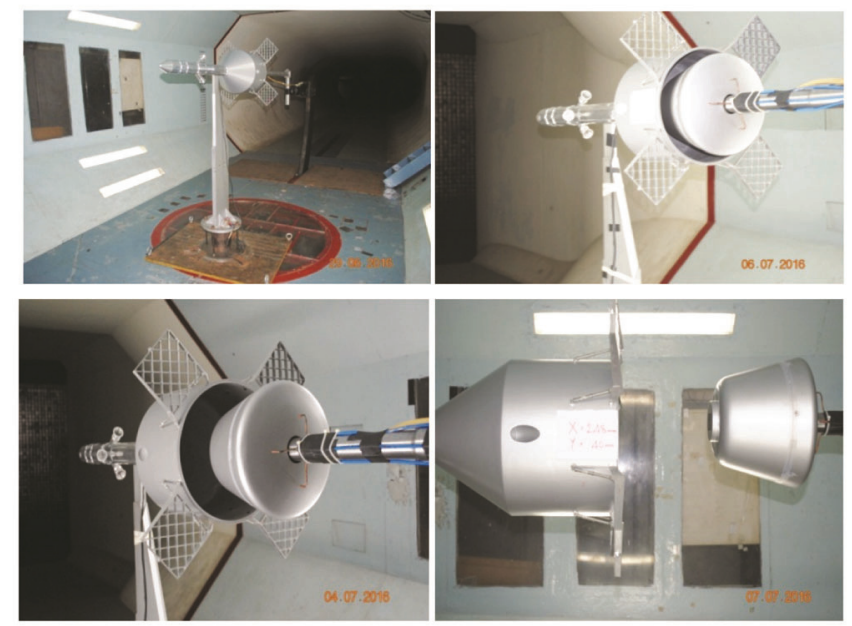

Figure 3. Crew Model separation studies in a wind tunnel.

the abort scenario is divided into three categories, namely launch pad abort, transonic abort and high-altitude abort. The design strategy of CES is the passive control to make the vehicle statically stable throughout its regime based on various design parameters such as ignition time, CM separation time, and total impulse and thrust level.

The pad abort mission profile is shown in Figure 2 where the vehicle reaches an altitude of $2.91 \mathrm{~km}$ with a speed of $47.5 \mathrm{~m} / \mathrm{s}$ at $t=20 \mathrm{sec}$. At this stage, CM is just about to separate from CES and is moved away from CES around $t=29 \mathrm{sec}$. After the separation of CM from CES, the parachute is deployed for safe recovery of former after removal of apex cover at $t=29.26 \mathrm{sec}$. During parachute deployment, the required orientation of CM attitude is attained in such a way that the velocity vector is aligned opposite to parachute drag and hence reorientation system (active) is incorporated before separation. Subsequently, pilot chute as well as drag chute are deployed and the final descent phase is achieved through the main parachutes before flashing into the sea.

The primary objective of the present study is to experimentally characterize the aerodynamic coefficients during CM separation from CES through wind-tunnel tests.

\section{Model, facility and test conditions}

Tests are carried out on $1: 10$ models of CES and CM in low-speed Open Circuit Wind Tunnel at the Indian Institute of Science (IISc), Bengaluru. Figure 3 shows the model mounted in the tunnel. Figure 4 shows the sign convention followed in the data processing. A sixcomponent strain gauge balance is used to measure forces and moments on CM during separation from CES. These forces and moments are measured on $\mathrm{CM}$ at different separation locations, namely $X / D=0,0.239,0.416$, $0.539,0.77,0.97,1.17,1.57$ and 1.71 (Figure 5), where $X$ 
is the longitudinal distance and $D$ is the diameter of the CM. Table 1 presents the test conditions.

\section{Results and discussions}

\section{Effect of variation of $X / D$}

Axial force coefficients on CM. The aerodynamic coefficients of $\mathrm{CM}$ alone during separation are considered in the present case and are presented in Figures 6-11 for a range of angles of attack $(\alpha)$ varying from $-5^{\circ}$ to $5^{\circ}$ with various $X / D$ from 0 to 2 for $Y / D=0$, where $Y$ is the lateral distance. It can be seen that the aerodynamic coefficients such as axial as well as normal force coefficients and the pitching moment coefficient about the nose are insensitive up to $X / D=0.2$ for various angles of attack due to the fact that the flow approaching CM is masked by the presence of CES. Though the aerodynamic coefficients are insensitive, as the angle of attack increases the aerodynamic coefficients respond to the flow, which can be observed from the plots. It can be seen from the axial force coefficient plot as shown in Figure 6, that beyond $X / D=0.2$ to 0.6 , there is drastic reduction. This is due to
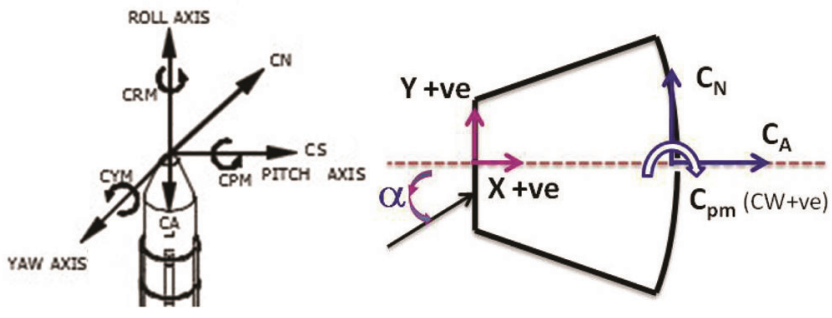

Figure 4. Sign convention.

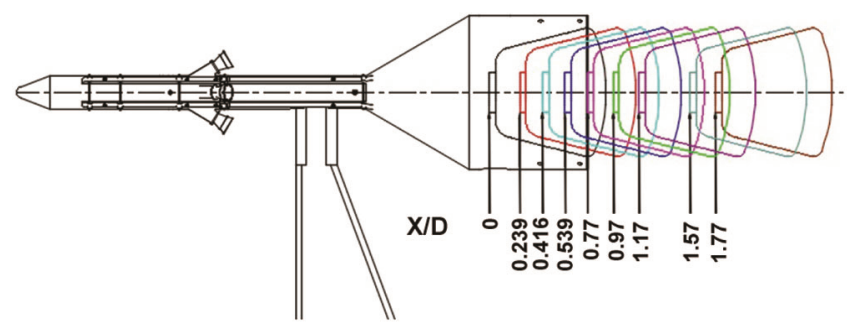

Figure 5. Different separation locations of the Crew Module (CM).

Table 1. Test conditions

\begin{tabular}{ll}
\hline Parameters & \multicolumn{1}{c}{ Values } \\
\hline Velocity & $45 \mathrm{~m} / \mathrm{s}$ \\
Reynolds number based on Crew Module (CM) & 0.85 million \\
$\quad$ diameter & \\
Reynolds number based on Crew Escape System & 3.8 million \\
$\quad$ (CES) model length & $\pm 5^{\circ}$ \\
Angle of attack & $0^{\circ}$ \\
Side slip angle of CM and CES &
\end{tabular}

CURRENT SCIENCE, VOL. 120, NO. 1, 10 JANUARY 2021

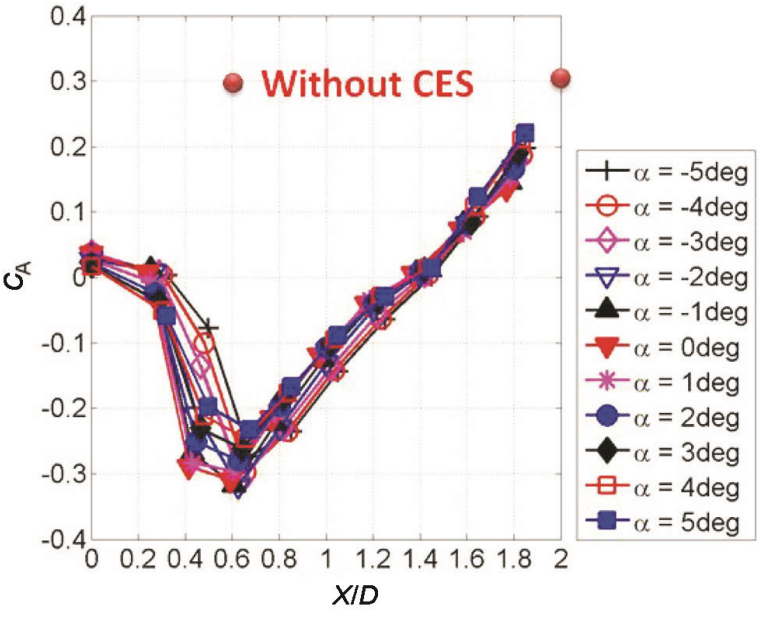

Figure 6. Axial force coefficients on $\mathrm{CM}$ w.r.t. $X / D$ (for different $\alpha$, $Y / D=0)$.

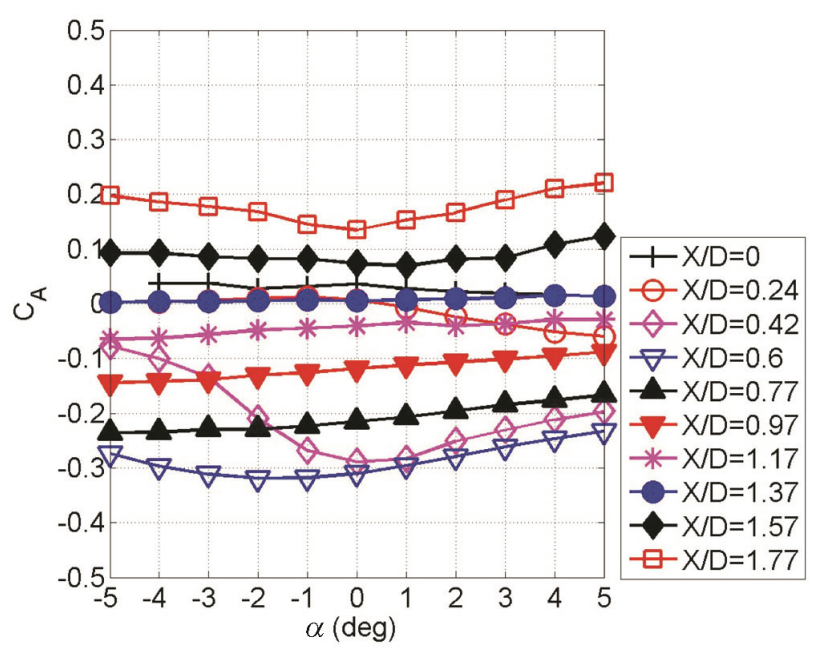

Figure 7. Axial force coefficients on $\mathrm{CM}$ w.r.t. $\alpha$ (for different $X / D$, $Y / D=0)$.

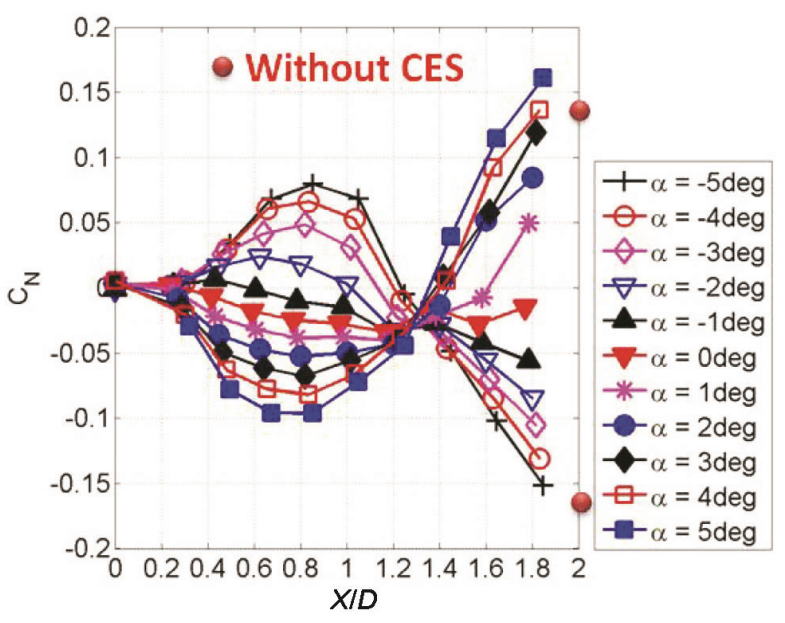

Figure 8. Normal force coefficients on $\mathrm{CM}$ w.r.t. $X / D$ (for different $\alpha, Y / D=0)$. 
suction effect, where the forward face of $\mathrm{CM}$ experiences a negative pressure since it is in proximity of the CES wake and hence, the axial force coefficient is negative. On the other hand, beyond $X / D=0.6$, the axial force coefficients for different angles of attack increase and the maximum value occurs at $X / D=1.77$. This shows that the effect of the CES wake is felt up to $X / D=0.6$ beyond which irrespective of angle of attack, the axial force coefficient $\left(C_{\mathrm{A}}\right)$ increases. It is observed that the value of $C_{\mathrm{A}}$ without CES is 0.3 at $X / D=2$ and the trend of $C_{\mathrm{A}}$ for $\mathrm{CM}$ in the presence of CES approaches this value beyond $X / D=1.8$. This clearly shows that the interference effect still exists. Figure 7 presents the cross plot of $C_{\mathrm{A}}$ with angle of attack. It is observed that the influence of the CES wake on CM is seen from $X / D=0.42$ to 1.17 , irrespective of angle of attack.

Normal force coefficients on CM. Similar to the earlier case, the normal force coefficient $\left(C_{\mathrm{N}}\right)$ is insensitive up to $X / D=0.2$ (Figure 8). It is observed that the wake effect

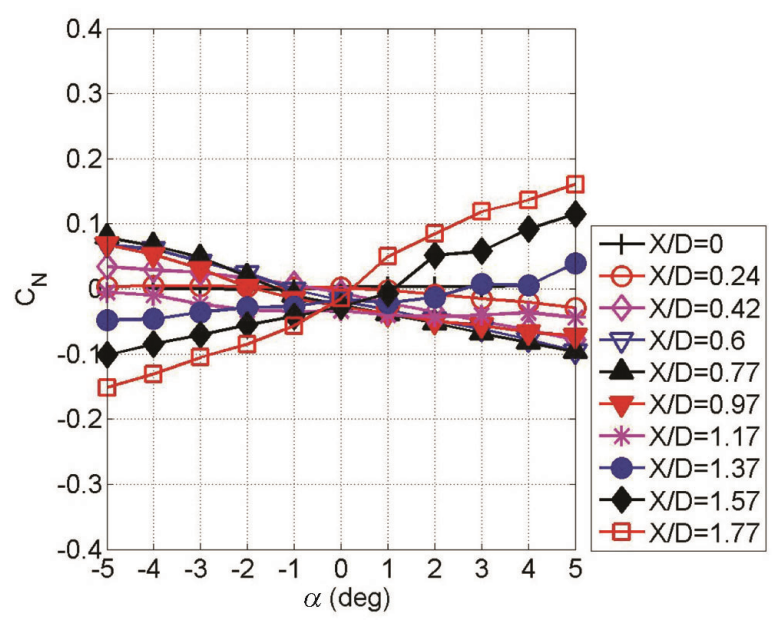

Figure 9. Normal force coefficients on $\mathrm{CM}$ w.r.t. $\alpha$ (for different $X / D, Y / D=0)$.

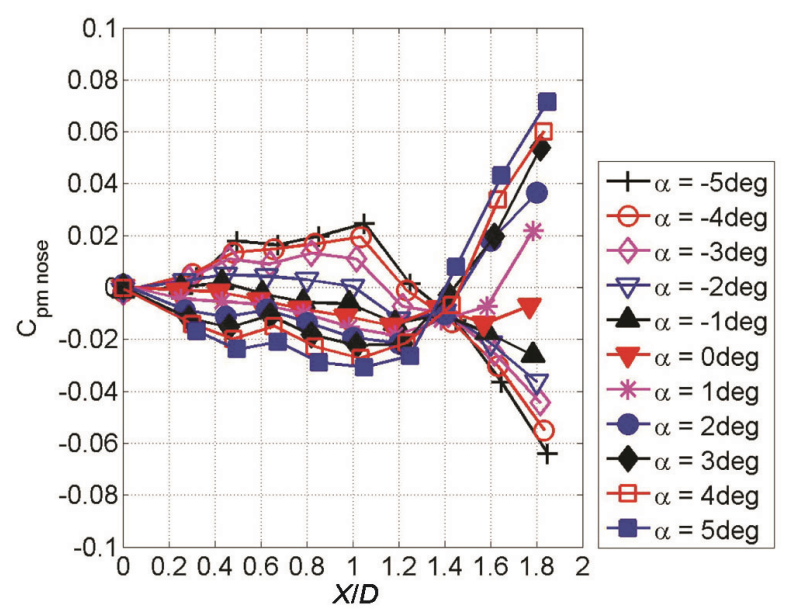

Figure 10. Pitching moment coefficients on $\mathrm{CM}$ w.r.t. $X / D$ (for different $\alpha, Y / D=0$ ). of CES is seen approximately till $X / D=0.8$. Once the angle of attack in the positive side, the $C_{\mathrm{N}}$ is in the negative side due to suction effect. However. CM is interference-free beyond $X / D=0.8$, where continuous increase in $C_{\mathrm{N}}$ is observed for positive angles of attack. Similarly, $C_{\mathrm{N}}$ decreases continuously by increasing negative angles of attack. In both cases, the trend reversal could be seen at $X / D=1.37$. It is also observed that from $X / D=0.8$ to 1.37, transition takes place where continuous increase and decrease in $C_{\mathrm{N}}$ values are seen for positive and negative angles of attack respectively. The cross plot of $C_{\mathrm{N}}$ in terms of angle of attack presented in Figure 9 also shows similar behaviour. It is observed that the value of $C_{\mathrm{N}}$ without CES is 0.14 and $C_{\mathrm{N}}$ for $\mathrm{CM}$ in the presence of CES at above $4^{\circ}$ indicates that $\mathrm{CM}$ is free from interference effect. However, below $4^{\circ}$ angle of attack, interference is seen.

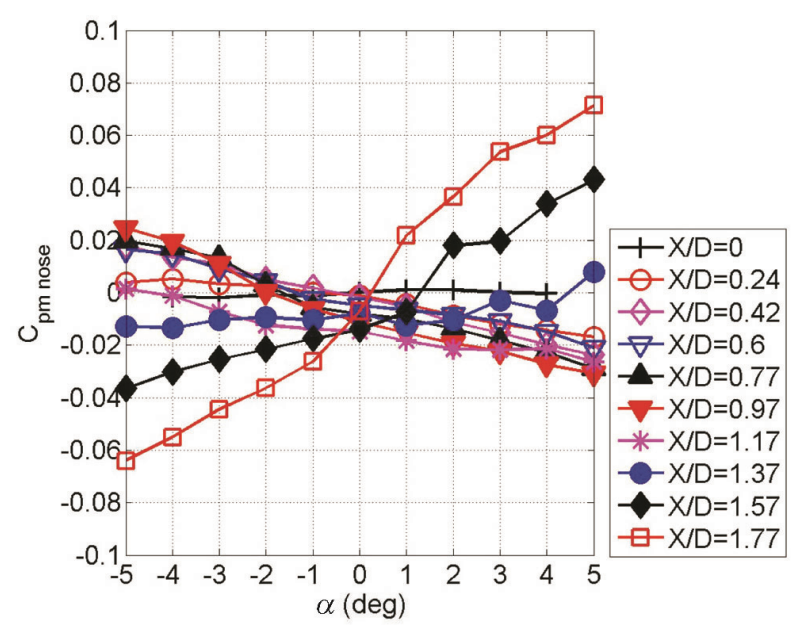

Figure 11. Pitching moment coefficients on $\mathrm{CM}$ w.r.t. $\alpha$ (for different $X / D, Y / D=0)$.

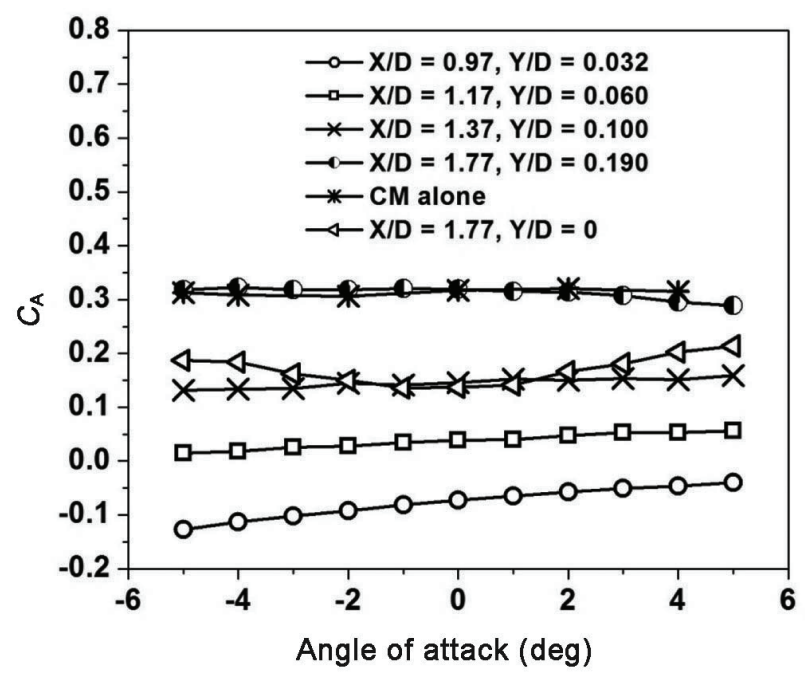

Figure 12. Axial force coefficients on $\mathrm{CM}$ w.r.t. $\alpha$ (for different $X / D$, $Y / D)$.

CURRENT SCIENCE, VOL. 120, NO. 1, 10 JANUARY 2021 


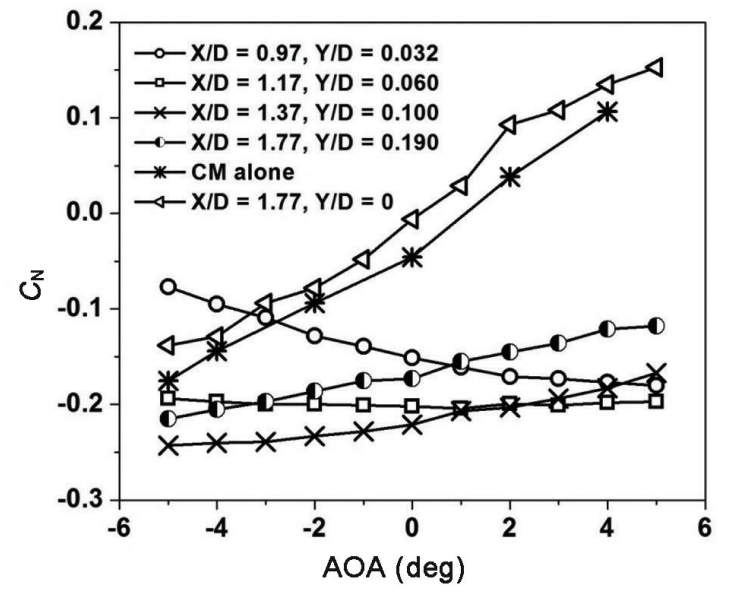

Figure 13. Normal force coefficients on CM w.r.t. $\alpha$ (for different $X / D, Y / D)$.

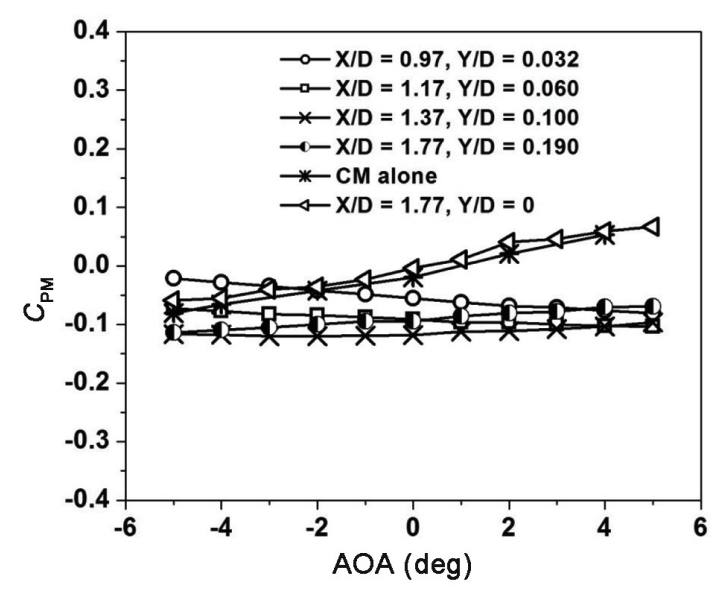

Figure 14. Pitching moment coefficients on $\mathrm{CM}$ w.r.t. $\alpha$ (for different $X / D, Y / D)$.

Pitching moment coefficients on CM. Similarly, the pitching moment coefficient about the nose $\left(C_{\mathrm{pm}}\right)$ is presented in Figures 10 and 11 respectively, in terms of $X / D$ and $\alpha$. Irrespective of angle of attack (Figure 10), pitching moment coefficient increases up to $X / D=1$, beyond which it decreases. An inflexion point is seen around $X / D=1.4$, where the trend is reversed. This is in line with the distribution of normal force coefficient as discussed earlier. Hence, $C_{\mathrm{pm}}$ about the nose is also influenced by the CES wake up to $X / D=1.4$, after which it is independent of the presence of CES, which is evident from rapid change in the slope. The static stability of the CM vehicle can approximately be ascertained through variation of $C_{\mathrm{pm}}$ with respect to angle of attack (Figure 11). It is observed that $C_{\mathrm{pm}}$ is negative up to $X / D=1.37$, indicating the vehicle is statically stable with angle of attack. Beyond $X / D=1.37, \mathrm{CM}$ is statically unstable for all angles of attack.

\section{Effect of variation of $Y / D$ on aerodynamic coefficients}

In the preceding section, $X / D$ movement alone is considered and aerodynamics of the separating body (CM) is studied. In the present case, both axial as well as lateral displacement of the separating body (CM) aerodynamics are considered at discrete locations, namely $X / D=0.97$, $1.17,1.37$ and 1.77 as well as $Y / D=0.032,0.06,0.1$ and 0.19 , and plotted (Figures 12-14). The effect of axial as well as lateral displacement of the separating body and the wake effect are clearly captured in these plots. In all cases, as the axial distance increases along with increasing lateral shift and the wake influence becomes weaker which is evident from the aerodynamic coefficients. From Figure 12, the wake effect is seen up to $X / D=1.37$ and $Y / D=0.1$. Once $\mathrm{CM}$ is placed at $X / D=1.77$ and $Y / D=0.19$, the axial force coefficient almost matches with CM data alone. On the other hand, if there is separation without lateral off-set (i.e. $Y / D=0$ at $X / D=1.77$ ), there exists a wake influence. On the other hand, for $C_{\mathrm{N}}$ and $C_{\mathrm{m}}$ (the pitching moment coefficient about the centre of gravity) as shown in Figures 13 and 14, wake influence still persists.

\section{Conclusion}

Experiments are carried out through wind-tunnel tests to characterize the aerodynamic behaviour of CM during its separation from CES. It is observed that the wake effect of CES greatly affects CM separation. In the present case, both axial and lateral shift of CM are considered and the aerodynamic coefficients are obtained to study the clean separation. From these studies, values of $X / D=1.77$ and $Y / D=0.19$ are required to separate CM from CES without any wake effects.

doi: $10.18520 / \mathrm{cs} / \mathrm{v} 120 / \mathrm{i} 1 / 105-109$ 